\title{
Disturbed testicular descent in the rat after prenatal exposure to the antiandrogen flutamide
}

\author{
P. van der Schoot
}

Department of Endocrinology and Reproduction, Faculty of Medicine and Health Sciences, Erasmus University Rotterdam, PO Box 1738, 3000 DR Rotterdam, The Netherlands

Summary. Exposure of rats in utero to the anti-androgen flutamide resulted in feminization of the external genitalia that was noticeable at birth. This exposure also resulted in a high degree of cryptorchidism during adulthood. In most affected animals, testes were lying in 'ovary position' close to the caudal pole of the ipsilateral kidney. Cryptorchidism occurred despite normal prenatal development of the gubernacular cones and the transformation of these structures, postnatally, into muscular cremaster sacs.

Inter- and intralitter variation in the response to prenatal exposure to flutamide was observed as well as intra-individual variation. Cryptorchidism frequently occurred unilaterally with right side cryptorchidism predominating.

Cryptorchidism occurred in association with marked suppression of the growth of the ipsilateral epididymis and deferent duct. The possibility is considered that the poor development or absence of these structures contributes to cryptorchidism. Intraindividual variation supports the concept of the local nature of the influence of testis hormones in stabilization and further differentiation of the ipsilateral Wolffian duct derivatives.

Cryptorchidism was enhanced when rats were treated postnatally with testosterone or oestradiol. The effect of testosterone was unexpected in view of the generally held hypothesis that androgens enhance testis descent. The effect of oestradiol was as expected: other animal models have been described in which induction of cryptorchidism by oestradiol occurs. Additional treatment with oestradiol caused further suppression of growth of the epididymis and deferent duct.

The response to prenatal exposure to flutamide was not altered by further injections of flutamide postnatally. Such injections were without effect in males not exposed to flutamide prenatally except for minor, but statistically significant, testicular enlargement during adulthood.

A model is thus presented that describes cryptorchidism as an endogenous developmental disorder.

Keywords: anti-androgen; flutamide; testis descent; cryptorchidism

\section{Introduction}

Testicular descent can be considered to be part of the somatic sexual differentiation process. The process would therefore be expected to obey the general law of masculine somatic sexual differentiation, i.e. it would depend on early secretion of testicular androgens (Jost et al., 1973). However, individuals affected by disturbed descent do not necessarily show signs of androgen deficiency and androgen treatment has no convincing effect (Hazebroek et al., 1987). Male pseudohermaphroditism, as the consequence of androgen insensitivity, may also be associated with 
descended testicles (Wilkins, 1950; Polani, 1970). Despite many investigations, disturbed testicular descent in humans represents a disorder with unknown aetiology (Hutson et al., 1990a).

Testicular descent requires the formation of the male-specific muscular cremaster sacs. In rats, these sacs develop from the gubernacular cones (Raynaud, 1958; van der Schoot, 1992). These organs grow as papilla-like structures from the bottom into the lumen of the abdominal cavity between days 16 and 19 of prenatal life. Within a few days of birth, these papillae invert and the inner wall of the papillae differentiates into the muscular cremaster sac. Recent experiments have indicated that both the prenatal gubernacular cone development and its postnatal inversion are independent of androgens. Postnatal inversion seems to occur independently of testis hormones (van der Schoot, 1992).

Formation of the cremaster sacs provides a necessary but, by itself, insufficient condition for testicular descent. Once a sac has been formed, the ipsilateral testis with its adjoining epididymis and deferent duct has to find its way from the surroundings of the caudal pole of the kidney to the bottom of the cremaster sac. This path is marked by the gubernacular cord, a peritoneal fold (ligament) extending between the testis and epididymis on one side and the tip of the gubernacular cone on the other. The cord must become sufficiently reduced in length to allow the testes to become contained within the cremaster sacs. Little is known about the mechanisms involved in this reduction and this study aimed to contribute new understanding in this respect. The effect of prenatal exposure to the anti-androgen flutamide (Neri et al., 1972; Peets et al., 1974) on the development of the gubernacular cones and the cremaster sacs and on testicular descent was examined. In addition, newborn rats, exposed prenatally to flutamide, were treated with testosterone or oestradiol to examine the effects of these hormones on flutamide-induced cryptorchidism. Testosterone was injected because of the ability of androgens to treat cryptorchidism (e.g. Hamilton, 1938) and oestradiol was injected because of its action in facilitating cryptorchidism (Raynaud, 1958).

\section{Materials and Methods}

\section{Animals}

Two- to three-month-old male and female Sprague-Dawley rats (Harlan Sprague Dawley, Madison, Wisconsin, USA) were caged together. The day on which copulatory plugs were found in the vagina was designated as day 0 of pregnancy. From day 11 of pregnancy females were injected (s.c.) daily with $10 \mathrm{mg}$ flutamide (4-nitro-3-trifluoromethyl-isobutyr-anilide, SCH 13521, Schering Ltd, Bloomfield, New Jersey). Flutamide was dissolved in $0 \cdot 1 \mathrm{ml}$ propanediol. Control animals received injections of solvent only. Day 11 was chosen to ensure exposure of the fetuses to flutamide throughout the period of androgen-dependent male sexual differentiation which is judged to start after day 13. Daily injections continued until newborn litters were found, usually by day 22 . The dose was chosen after preliminary studies had revealed that $10 \mathrm{mg}$ per day was near to the maximum dose not visibly impairing the health of the pregnant animals.

Postnatal injections of $0.25 \mathrm{mg}$ flutamide in $0.05 \mathrm{ml}$ solvent or solvent only were given every other day from birth up to and including day 9 .

\section{Experiment 1. Development of male and female animals after prenatal, postnatal or pre- and postnatal exposure to flutamide}

All newborn animals were marked (by toe clipping) to allow for individual recognition. Flutamide-exposed males were indistinguishable at birth from females owing to their failure to develop genital masculinization and to lose their nipples. Bodyweight was recorded once a week until autopsy.

All animals developed a vaginal opening. Daily vaginal smears were taken from the females to ascertain cyclicity. Once normal vaginal cycles had been established, a sample of females was examined for fertility by studying the outcome of their caging with males of known fertility. Vaginal smears were also taken from the flutamide exposed males and examined.

Testis position in adults was examined by palpation. At autopsy genital anatomy was studied carefully. Testis position, testis and internal and external genitalia development were recorded.

\section{Experiment 2. Cremaster sac development in infancy after prenatal exposure to flutamide}

Seven-day-old rats from three different litters that had been exposed to flutamide prenatally were killed by cervical dislocation. The lower abdomen was fixed in Bouin's solution. Frontal sections $(10 \mu \mathrm{m})$ were mounted serially and 
stained with haematoxylin and eosin. The lower abdomen of rats that had been exposed to flutamide prenatally but had been castrated at birth was also studied.

\section{Experiment 3. Effect of treatment with testosterone or oestradiol in infancy on the development of futamide-induced cryptorchidism}

Newborn rats that were exposed prenatally to flutamide, were injected s.c. with testosterone propionate $(0.1 \mathrm{mg}$ in $0.1 \mathrm{ml}$ olive oil) or oestradiol benzoate $(0.01 \mathrm{mg}$ in $0.01 \mathrm{ml}$ olive oil) on days $1,3,5,7,9$ and 11 of postnatal life.

Rats treated with testosterone were killed at 60 days of age as male-female distinction had become unequivocal at that time. Rats treated with oestradiol were killed between 49 and 140 days of age. As animals grew it was easier to distinguish between males and females, but even at 140 days of age some males had not developed any external sign by which their sex could become identified correctly.

\section{Experiment 4. Intra-abdominal pressure and development of cryptorchidism}

We examined the possible effect of increased intra-abdominal pressure on the development of cryptorchidism.

Newborn males were killed and the abdominal skin was removed to show the genital area and lower abdominal muscles. Application of manual pressure to the abdomen of newborn males resulted in immediate and reversible eversion of the gubernacular cones. They projected as 'fingers' or 'antlers' from the lower abdomen into a caudal/ lateral direction. This procedure allowed the unequivocal distinction between normal males and females and between the male and female offspring of flutamide injected mothers.

The effect of this procedure was then investigated with intact animals. Males, irrespective of prenatal exposure to flutamide, showed extrusion of transparent small 'canals' on either side of the external genital, a sign of eversion of the developing cremaster muscle sac. The canal disappeared upon removal of the pressure to the abdomen.

The effect of this increased abdominal pressure was examined by repeating this procedure several times a day throughout days 1-15 in 12 male rats treated with flutamide. The animals were killed at age 60 days and testis position was recorded.

\section{Statistical analysis}

Experimental results were evaluated using parametric one-way or two-way analysis of variance and the further analysis of significant overall differences with Tukey's HSD-test. Nonparametric tests included $\chi^{2}$ square tests and Fisher exact probability tests (Kirk, 1968). $P=0.05$ was adopted as the lower limit of the probability for statistical significance of differences between groups.

\section{Results}

\section{Experiment 1. Effect of prenatal exposure of male and female rats to flutamide}

At birth, males and females exposed prenatally to flutamide could not be distinguished. All had a feminine appearance including a clitoris, clitoral urethra and nipples. From about day 40 , males could be distinguished from females in several respects. Inguinal hernial sacs developed on the lower abdomen with or without testes palpable within them. The clitoris became enlarged in males and the preputial skin became loose from the underlying clitoral glans. Body hair gradually lost its 'soft' female aspect and long strong hairs, typical of normal males, developed. The most significant distinction was the difference in body weight. Males took the 'masculine' path from about day 40 as did control males, whereas all females followed the 'feminine' path (Figs la, b).

Both females and flutamide-exposed males developed a vaginal orifice and opening. The vaginal opening in males was markedly smaller than in females. However, vaginal smears could be taken from both groups. Female animals showed normal vaginal cycles. All males showed vaginal smears containing mucus, leucocytes and epithelial cells. However, vaginal smears with motile or nonmotile spermatozoa were found consistently with some of the male animals.

At day 90, six flutamide-treated females were mated with fertile males. All became pregnant and delivered healthy litters of 11-16 pups after pregnancy of normal duration.

Male rats were autopsied between day 90 and 140 (Table 1). All animals showed cremaster sacs that had grown in the proper caudal direction (Fig. 2a). Half of these sacs contained the 

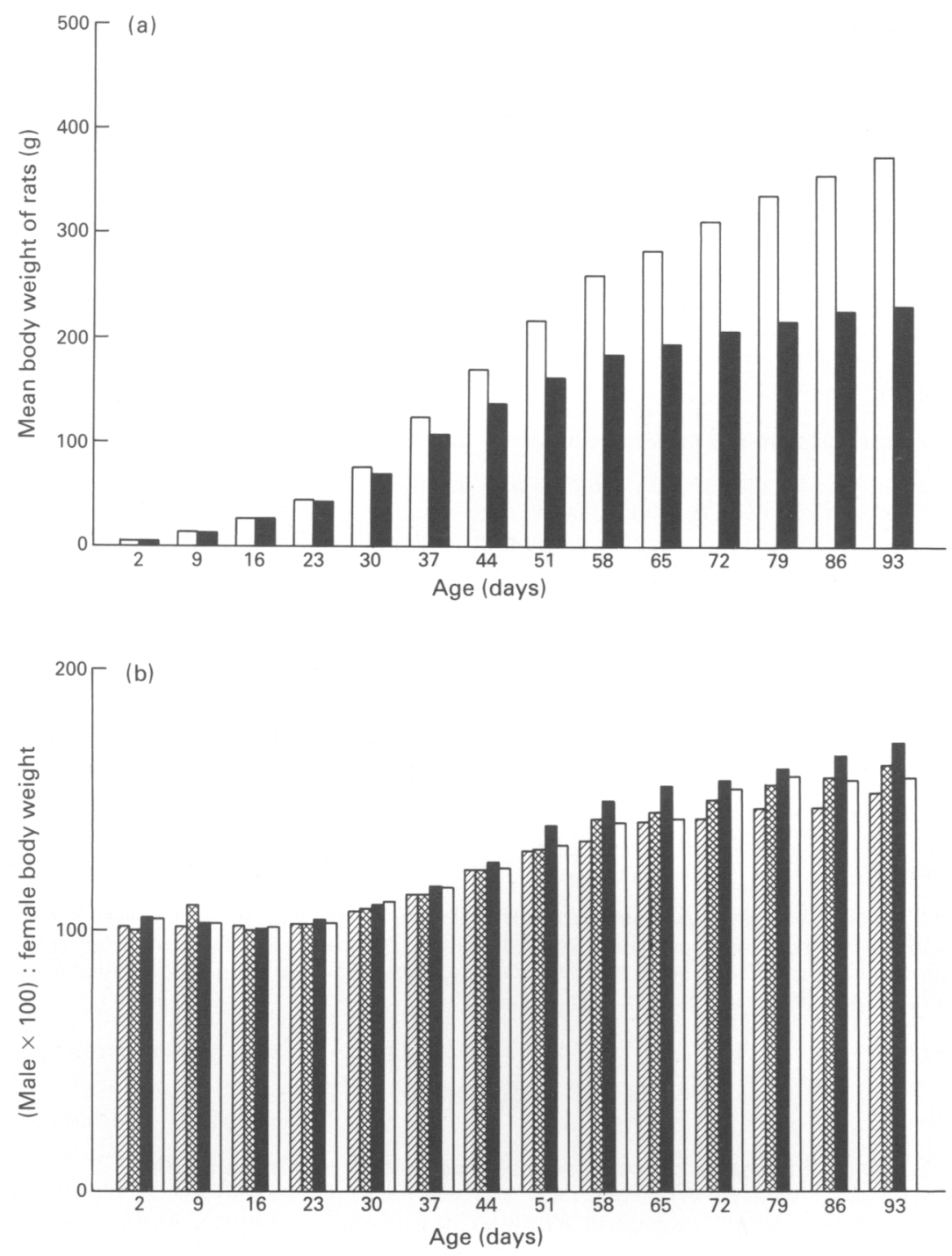

Fig. 1. (a) Effect of treatment with flutamide prenatally and postnatally on bodyweight of male ( $\square n=45$ ) and female ( $\square n=53$ ) rats. (b) Comparison of bodyweight among groups of male and four corresponding groups of female rats (8-14 animals per group) exposed to flutamide prenatally $(\bigotimes)$, pre- and neonatally ( neonatally $(\boldsymbol{G})$ or not exposed to this compound $(\square)$. The male:female bodyweight ratio appeared independent of the type of treatment.

ipsilateral testis, whereas the remaining sacs were empty and the ipsilateral testes were found intraabdominally (Fig. 2b, c). The correlation between the size of the cremaster muscle and the weight of the ipsilateral testis was significant (correlation coefficient $0.77 ; P<0.001$ ). The flutamide-exposed males did not show signs of prostatic development. The male-specific musculature at the base of the penis was either absent or underdeveloped: for instance, the levator ani muscle weighed $15-20 \mathrm{mg}$ compared with the normal value of 200-300 mg.

Scrotal testes were of two types. 'Large testes' were properly connected to a completely developed epididymis and deferent duct which, in turn, opened at the tip of the short 'vagina'. Some of these testes and adjoining epidimydides showed macroscopic signs of infection. All testes showed 
Table 1. Weights of testes, epididymides and cremaster muscle sacs (mg) (mean \pm SEM) in rats exposed to flutamide prenatally or prenatally and postnatally (6 or more per group; groups combined) and autopsied at 90-140 days of age ${ }^{\mathrm{a}}$

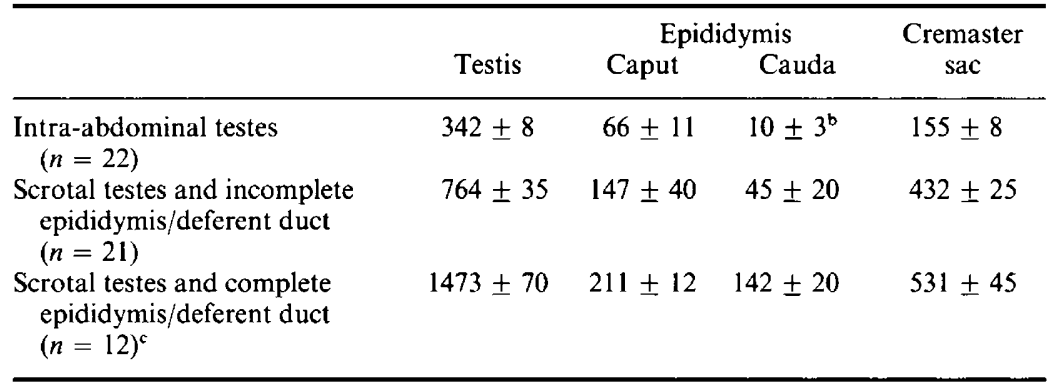

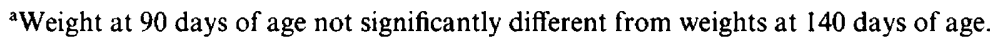

'Including 15 rats with right sided cryptorchidism with complete suppression of epididymis growth (weight $=0 \mathrm{mg}$ )

' Five scrotal testes which showed macroscopic signs of infections were not included.

microscopic signs of infection. There were leucocytic infiltrations resulting in partial or total organ destruction. These were the animals in which spermatozoa had been found in the vaginal smears. Histologically, the testes showed tubuli with normal spermatogenesis and tubuli destroyed by infection (Fig. 3a, b). Scrotal 'small testes' showed no connection with the adjoining epididymis and deferent duct. Sometimes, part of the epididymis, usually the isolated caput, and part of the deferent duct were present. In the case of partial deferent duct development, it was always the distal part that developed ending at the tip of the 'vagina'. The proximal part and caudal epididymis were usually absent. Histologically, these testes showed tubuli with and without signs of spermatogenesis.

Intra-abdominal testes were smaller than both types of scrotal testes. Most often they were lying close to the caudal pole of the ipsilateral kidney as if 'in the ovarian position' (Fig. 2c). They had vasculature with the normal pampiniform plexus appearance; the vasculature was connected in the usual fashion to the vena cava or vena iliaca. The caudal pole of the testes was connected via a long 'ligament' to the lower end of the ipsilateral cremaster sac (Fig. 2b, c). Intra-abdominal testicular position, rather than scrotal testis position, was associated with significantly inhibited development of epididymis and deferent duct (Table 1). Right side development was significantly less in this respect than left side development. There were more intra-abdominal testes on the right than on the left side but the difference did not reach statistical significance when the data from three similar studies were combined (57 rats: 32 intra-abdominal testes right; 25 intra-abdominal left: $\chi^{2}=1 \cdot 2$; $P=0 \cdot 27$ ). Histologically, intra-abdominal testes showed tubuli without spermatogenesis and, occasionally, patches filled with large numbers of Leydig cells (Fig. 3c, d).

In all rats, seminal vesicles could be clearly identified. Microscopic examination of their contents revealed the presence of spermatozoa in most rats that had ipsilateral 'large' scrotal testes and, thus, an open connection between testis and vaginal lumen (Fig. 4a, b). In all rats, four ducts, ending at the tip of the vagina, could be identified: the left and right deferent ducts and the seminal vesicles.

Postnatal injections of flutamide caused no externally visible alterations in genital development. At autopsy, however, testes weight of treated animals was significantly greater than that of control animals (Table 2).

\section{Experiment 2. Cremaster sac development in infancy after prenatal exposure to flutamide}

Seven rats were studied that had been exposed to flutamide prenatally and given no further treatment after birth. Nine testes were located in the lower abdomen close to the 'neck' of the 

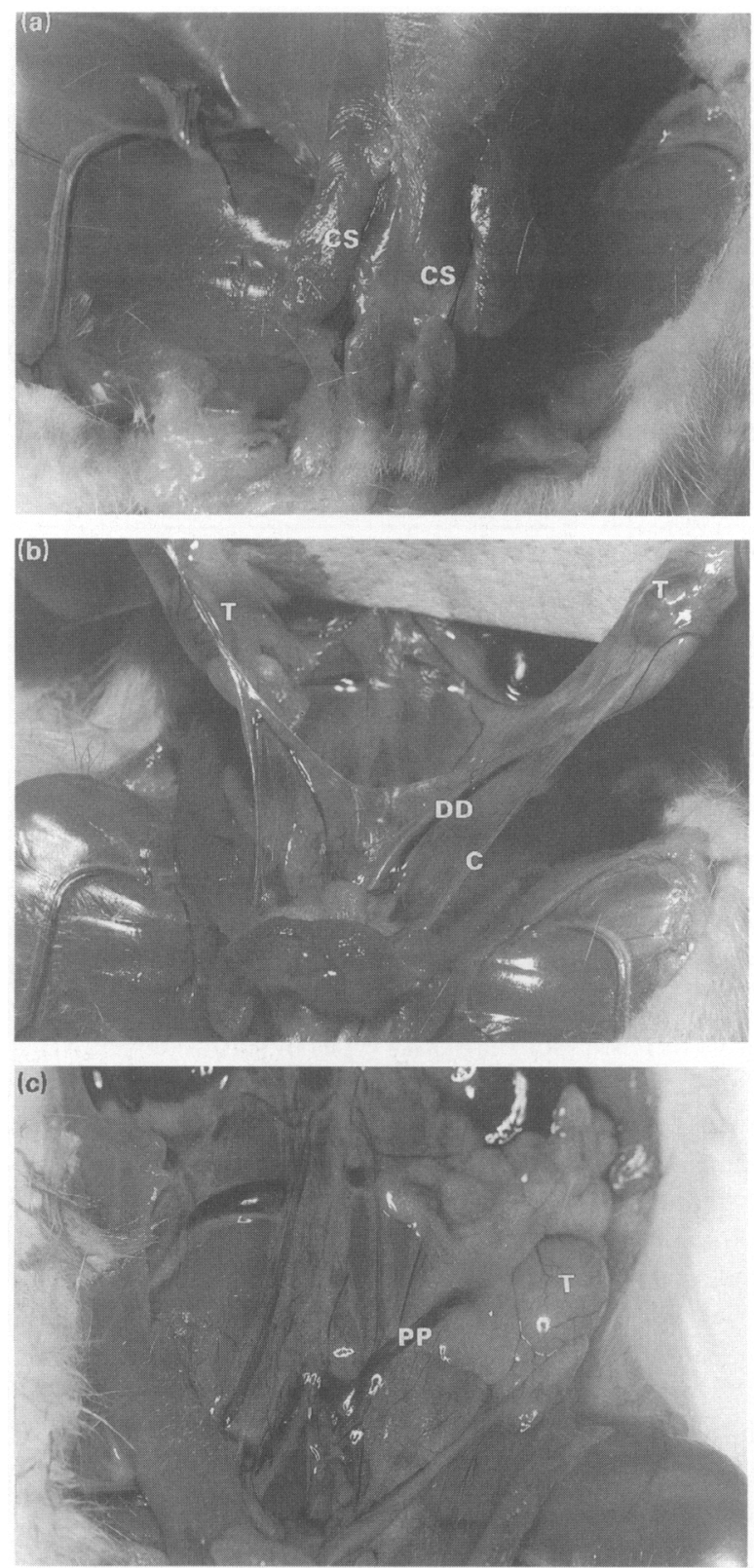

Fig. 2. (a) Aspect of the lower abdomen wall (skin removed) of an adult male rat exposed to flutamide during prenatal life. Empty cremaster sacs (CS) emerge from the lower abdomen and are properly directed caudally. There are no palpable testes contained within these sacs. (b) Abdominal contents of the same rat as in (a). Testes (T) are lying intra-abdominally. There were no epididymidal remnants on either side. To the right, a minor part of the deferent duct was present behind the wall of the bladder (not visible). To the left the deferent duct (DD) measured $3 \mathrm{~cm}$ : distally it was connected to the tip of the vagina behind the bladder (not visible) and proximally it ended blindly. The testes were provided with long 'ligaments' $(C)$, developed from the gubernacular cords. which connected the caudal testes poles with the bottom of the ipsilateral cremaster sac. (c) Intra-abdominal testis ( $T$ ) of another animal, lying close to the ipsilateral kidney. The testicular vasculature (pampiniform plexus: PP) is running in a mediocaudal direction 

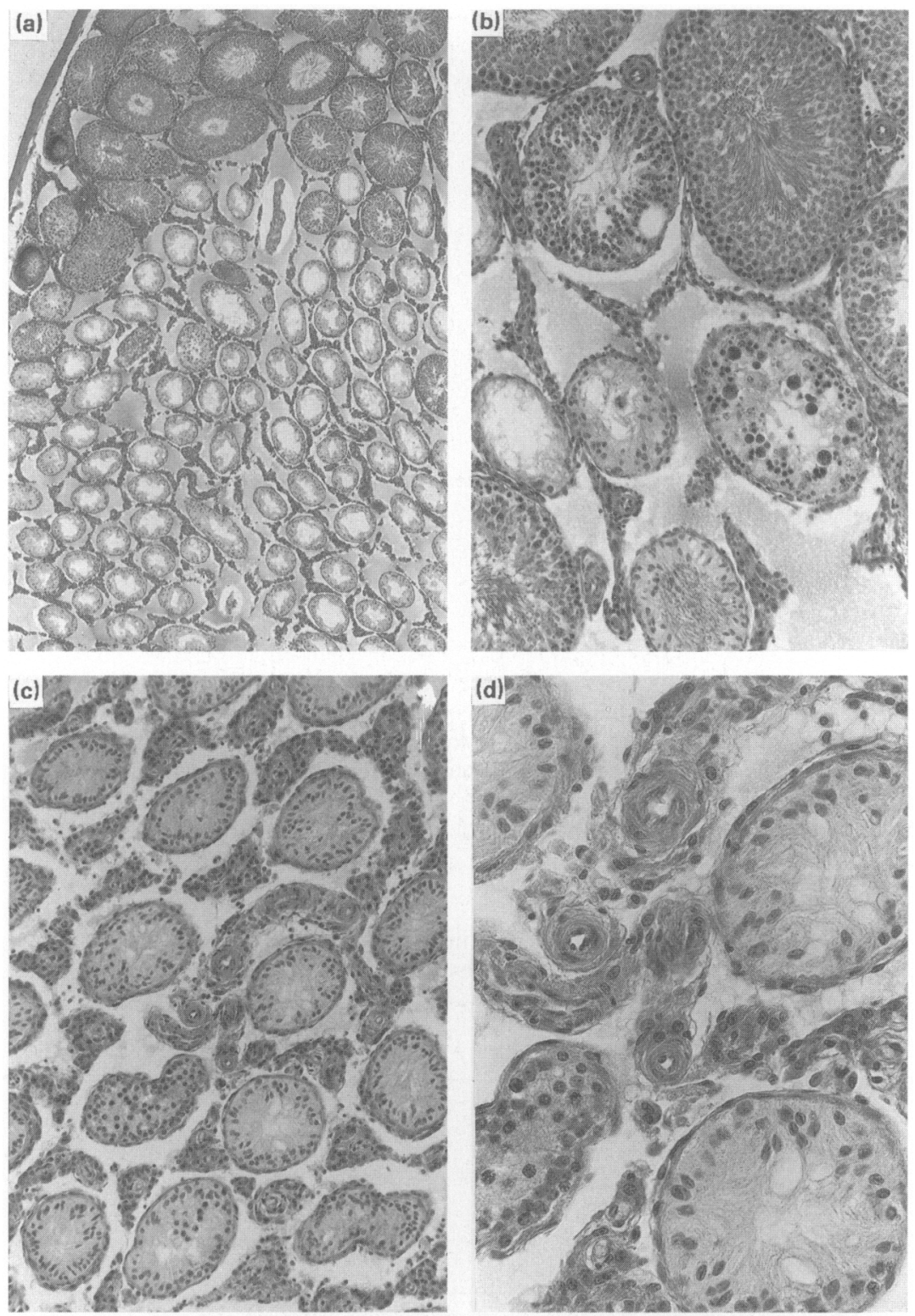

Fig. 3. (a) Histological section of a scrotal testis of a rat exposed to flutamide prenatally and having an open connection via the epididymis and deferent duct with the vagina. The upper part of the section shows areas of tubuli with apparently normal spermatogenesis. The tubuli in the lower part of the section do not show normal spermatogenesis $(\times 20)$. (b) Detail of the testis shown in (a) with 'normal' tubuli (upper part) and 'damaged' tubuli (lower part) $(\times 85)$. (c) Section of an intra-abdominal testis that lacked an adjacent epididymis from a rat exposed to flutamate prenatally. No tubuli showed spermatogenesis. Occasional large areas with Leydig cells were visible between the tubuli (compare with (b)) $(\times 85)$. (d) A detail of the section shown in (c). All tubuli appear 'damaged' and without spermatogenesis $(\times 210)$.

inverted gubernaculum (cremaster muscle sac). The remaining five testes were lying higher in the abdomen close to the caudal pole of the kidney. The ipsilateral gubernaculum had not inverted but was larger than normal at birth. The two positions were found coexisting in three animals (Fig. 5). 

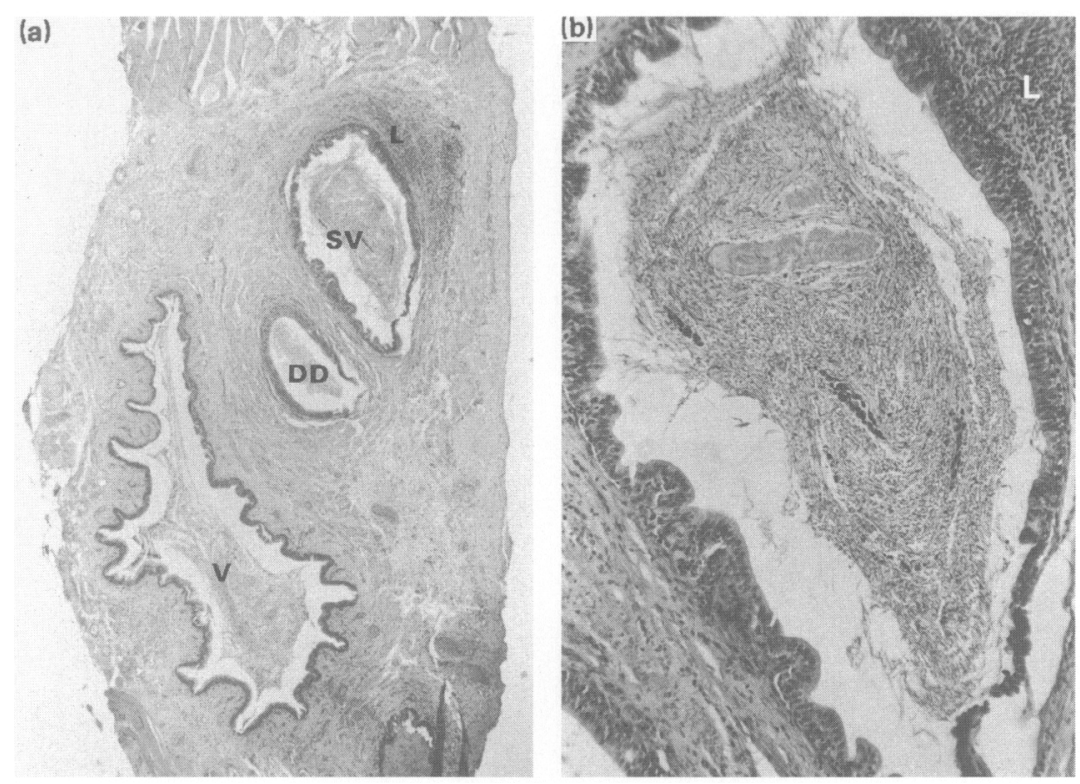

Fig. 4. (a) Histological section through the vagina (V), the right-sided deferent duct (DD) and seminal vesicle (SV) of a rat with an open connection between the testes and vagina. The vaginal lumen is filled with spermatozoa. Spermatozoa arrived via the deferent duct and also filled the lumen of the seminal vesicles. The seminal vesicle shows leucocytic (L) infiltrations indicating infection of the tissues $(\times 28)$. (b) Detail of (a) at higher magnification $(\times 90)$, showing the contents of the seminal vesicle lumen including spermatozoa.

Table 2. Weights of testes, epididymides and cremaster muscle sacs (mg) (mean \pm SEM) from adult rats exposed perinatally to flutamide ${ }^{a}$

\begin{tabular}{|c|c|c|c|c|}
\hline \multirow[b]{2}{*}{ Treatment } & \multirow[b]{2}{*}{ Testis } & \multicolumn{2}{|c|}{ Epididymis } & \multirow{2}{*}{$\begin{array}{c}\text { Cremaster } \\
\text { sac }\end{array}$} \\
\hline & & Caput & Cauda & \\
\hline $\begin{array}{l}\text { Flutamide prenatally } \\
\text { or pre- and postnatally } \\
\text { (12 testes in } 10 \text { rats) }\end{array}$ & $1473 \pm 70^{*}$ & $211 \pm 12^{*}$ & $142 \pm 20^{*}$ & $531 \pm 45$ \\
\hline $\begin{array}{l}\text { Flutamide postnatally } \\
\text { (16 testes in } 8 \text { rats) }\end{array}$ & $2047 \pm 30^{*}$ & $280 \pm 6$ & $248 \pm 3$ & $559 \pm 9$ \\
\hline $\begin{array}{l}\text { Solvent postnatally } \\
\text { (14 testes in } 7 \text { rats) }\end{array}$ & $1812 \pm 28^{*}$ & $291 \pm 7$ & $227 \pm 6$ & $539 \pm 15$ \\
\hline
\end{tabular}

${ }^{a}$ Only scrotal testes with complete epididymis/deferent duct were included.

*Significantly different from the two other groups (ANOVA + HSD; $P<0.01$ ).

In parallel with these animals, six flutamide-exposed rats that had been castrated at birth were studied. In all these animals the gubernacula had become inverted and developed into empty cremaster muscle sacs $(n=12)$.

\section{Experiment 3. Effect of treatment with testosterone or oestradiol in infancy on the development of flutamide-induced cryptorchidism}

Twelve rats treated with testosterone propionate after birth showed clitoral enlargement during the treatment period, indicative of the expected function of the injected androgen. At 50-60 days of 
Table 3. Effect of neonatal treatment with testosterone propionate on the weights (mg) at 60 days of age of testis, epididymis and cremaster muscle sac in rats following prenatal exposure to flutamide (mean \pm SEM)

\begin{tabular}{lcccc}
\hline Treatment & Testis & Epididymis & $\begin{array}{c}\text { Cremaster } \\
\text { sac }\end{array}$ & $\begin{array}{c}\text { Levator } \\
\text { ani }\end{array}$ \\
\hline $\begin{array}{l}\text { Flutamide prenatally } \\
\text { solvent only neonatally } \\
\quad(11 \text { rats) }\end{array}$ & $\begin{array}{r}635 \pm 100 \\
(45 \%)^{\mathrm{a}}\end{array}$ & $60 \pm 14$ & $158 \pm 18$ & $15 \pm 3$ \\
$\begin{array}{l}\text { Flutamide prenatally } \\
\text { testosterone neonatally } \\
(12 \text { rats) }\end{array}$ & $\begin{array}{r}184 \pm 65 \\
(80 \%)^{\mathrm{a}}\end{array}$ & $12 \pm 5$ & $66 \pm 13$ & $56 \pm 5$ \\
\hline
\end{tabular}

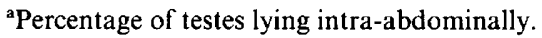

All results in rats given testosterone neonatally were significantly different from controls $\left(P<0.01\right.$ by Student $t$-test or $\chi^{2}$ test $)$.

age, the majority of the animals showed inguinal hernial sacs not containing testes. Testes were smaller than those of rats not treated with testosterone. Cryptorchidism occurred significantly more frequently in rats treated with testosterone after birth than in rats not treated with androgen. The weight of the levator ani muscle of testosterone-treated rats was significantly greater than in control animals (Table 3).

In animals treated postnatally with oestradiol benzoate most of the testes remained in the intraabdominal position. Inguinal hernial sacs developed at an advanced age in some animals but, at 140 days of age, all 15 rats showed cremaster sacs at autopsy. Their minor size contributed to the failure of reliable male-female distinction before death. The neonatal injections of oestradiol modified the external vaginal/urethral orifice in a similar fashion in both females and males also preventing the easy distinction between the sexes even at 140 days of age.

Testes growth was retarded by the treatment with oestradiol in infancy (Table 4). Failure of intra-abdominal testes to grow significantly between 83 and 140 days of age was taken as an index that final adult testis size had been reached. Postnatal treatment with oestradiol had virtually eliminated any further development of epididymis and seminal vesicles. In most rats, no remnants of the epididymis were observed, whereas the two seminal vesicles could be recognized but were very small.

\section{Experiment 4. Increased intra-abdominal pressure and development of cryptorchidism in flutamide exposed male rats}

Manual pressure to the abdomen caused extrusion of the now inverted gubernacula in all male rats. The response of males treated with flutamide did not differ from that of untreated males. Increasing intra-abdominal pressure in this way, throughout early development, did not affect the development of cryptorchidism. Only one of 12 rats had two orthotopic testes by 60 days of age, whereas in four rats both testes were located intra-abdominally. The remaining animals had either the left $(n=3)$ or the right $(n=4)$ testis in the abdomen.

\section{Discussion}

The contention that androgens play a role in testis descent lacks consistent experimental support. The regular occurrence of testis descent in animals and humans affected by the androgen insensitivity syndrome seems to exclude such a role (Wilkins, 1950; Polani, 1970; Stanley et al., 1973; Fentener van Vlissingen et al., 1988). However, androgens could affect testis descent indirectly through their modifying effects on the testes and genitalia (Heyns, 1987). Modifications 


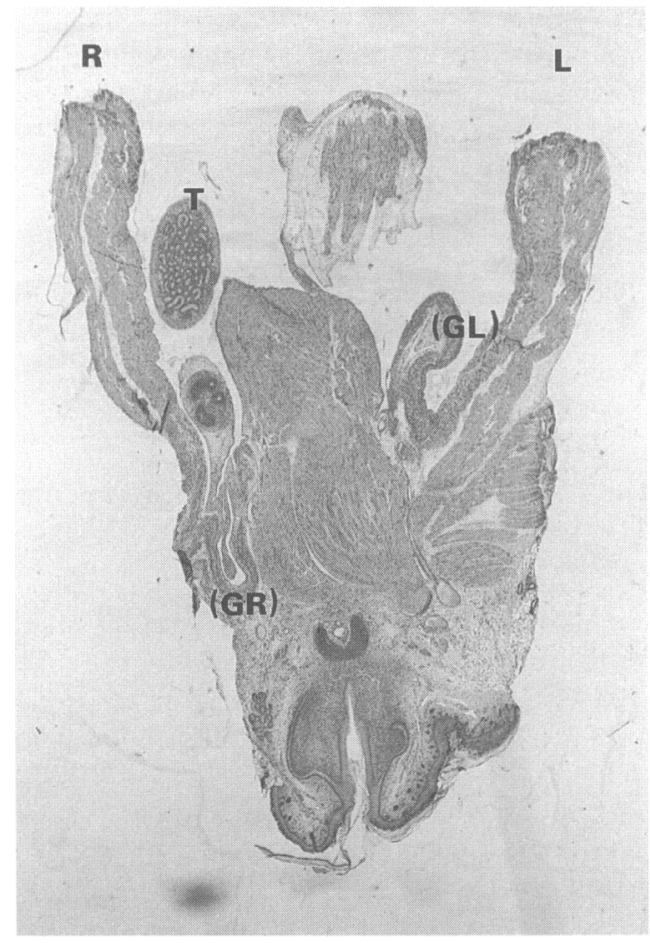

Fig. 5. Frontal section through the lower abdomen of a 7-day-old male rat exposed prenatally to flutamide. On the right side (R), the gubernaculum (GR) has become inverted on its way to becoming the wall of the muscular cremaster sac. The ipsilateral testis $(T)$ is in the process of testis descent. On the left side (L), the gubernaculum (GL) is larger than is normally found at birth. It is clearly differentiated in a darkly stained outer muscular wall and a lightly stained mesenchymatous core. The ipsilateral testis (not visible in the picture) was lying high in the abdomen close to the ipsilateral kidney.

Table 4. Effect of neonatal treatment with oestradiol benzoate on the weights $(\mathrm{mg})$ at 49,83 and 140 days of age of testis, epididymis and cremaster muscle sac in rats following prenatal exposure to flutamide (mean \pm SEM)

\begin{tabular}{lcccc}
\hline $\begin{array}{l}\text { Age } \\
\text { (days) }\end{array}$ & Testis & $\begin{array}{c}\text { Epididymis } \\
\% \text { animals with } \\
\text { suppression of } \\
\text { development }^{\mathrm{a}}\end{array}$ & weight & $\begin{array}{c}\text { Cremaster sac } \\
\% \text { animals with } \\
\text { suppression of } \\
\text { development }^{\mathrm{a}}\end{array}$ \\
\hline $49(n=12)$ & $\begin{array}{c}57 \pm 7 \\
(83 \%)^{\mathrm{b}}\end{array}$ & N.I. & $5 \cdot 4 \pm 2 \cdot 3$ & 50 \\
$83(n=18)$ & $\begin{array}{c}186 \pm 16 \\
(89 \%)^{\mathrm{b}}\end{array}$ & N.I. & $50 \pm 10$ & 22 \\
$140(n=15)$ & $\begin{array}{c}209 \pm 14 \\
(93 \%)^{\mathrm{b}}\end{array}$ & 81 & $59 \pm 9$ & 0 \\
\hline
\end{tabular}

$n$ : number of rats.

N.I.: organs not positively identifiable using macroscopic examination.

Weights of testis and cremaster sac at age 83 days not significantly different from age 140 days.

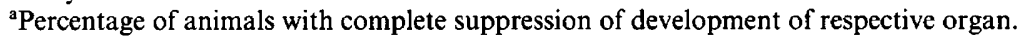

bPercentage of testes lying intra-abdominally. 
of the size of the genital organs could, by themselves, affect the chances of the testes and adjoining organs finding their way to the bottom of the muscular cremaster sacs.

The availability of an easy and reliable animal model for disturbed testis descent by interference with hormonal development of the animal is a prerequisite for any insight into the aetiology of cryptorchidism (Hazebroek et al., 1987; Hutson et al., 1990a). Cryptorchidism resulting from surgical procedures such as the transection of the gubernacular cones neonatally (Bergh et al., 1978; Beasley \& Hutson, 1988) or of the connection between the testis-epididymis complex and the bottom of the cremaster sacs later in life (e.g. Kort et al., 1990) are unlikely to provide insight into cryptorchidism as a developmental disorder.

Cryptorchidism occurred reproducibly in about $50 \%$ of rats in a series of experiments with Sprague-Dawley rats. In similar experiments by Brand et al. (1989) with Wistar rats, cryptorchidism did not occur but there was suprainguinal testicular ectopia in half of the rats. Strain-specific features in Sprague-Dawley rats may be of critical importance for the development of cryptorchidism and further work is required to investigate this. Suprainguinal ectopia after prenatal exposure to antiandrogen has been mentioned by other authors but has not been studied in detail (Neumann et al., 1970; Peets et al., 1974).

The present study aimed to examine testis descent in rats after their exposure to the antiandrogen, flutamide, during prenatal life. Although previous studies have revealed little or no effect of prenatal exposure to anti-androgens on testis descent (Neumann et al., 1970; Elger et al., 1971; Peets et al., 1974), a preliminary study, in which Sprague-Dawley rats were exposed to flutamide revealed a marked occurrence of cryptorchidism. This cryptorchidism occurred with considerable inter-litter, intra-litter and intra-individual variation. Variation within litters may indicate that fetuses become exposed with variable efficiency when drugs are injected into their mother. There may be subtleties in the maternal or placental circulation causing differences in the degree of exposure to flutamide. The nature of these subtleties is unclear. Intra-individual variation may indicate a difference between the vasculature of the left and right part of the developing gonadalgenital system. Further work is required to determine the nature of this difference.

Intra-individual variability is the surprising finding in the present study. Variability was not limited to unilateral cryptorchidism. The degree of interference by flutamide was also variable in the development of the Wolffian duct derivatives. Deferent duct and parts or the whole of the epididymis could be present on one side while the organs were completely lacking on the other. However, seminal vesicle growth occurred symmetrically in all rats examined. Jost et al. (1973) have provided convincing evidence of the local nature of developing testes to stabilize the Wolffian ducts. Intra-individual variability of the development of the Wolffian duct derivatives indicates that flutamide, reaching the developing systems of the fetus through the general circulation, probably has to compete with locally produced and locally acting testis hormones. Asynchronous pulsatility of hormone secretion by the left and right testes during fetal life could account for intra-individual variability. However, there could be other mechanisms; in this respect the difference in suppression of the umbilical artery between right and left side can be of significance. Development of the internal genitalia occurs in close proximity to the large umbilical vessels. In rats the left umbilical artery atrophies, whereas the right artery hypertrophies during the latter part of fetal life. Haemodynamics on the right side in an embryo may be different from the left side for this reason. In cases of unilateral cryptorchidism occurring on the right side, there was complete suppression of the Wolffian duct derivatives, whereas suppression on the left side was significantly less. Cryptorchidism in humans often occurs unilaterally with right-sided significantly outnumbering left-sided cryptorchidism (Heyns, 1987). Some specific anatomical features in humans may also play a role in the preponderance of right-side cryptorchidism.

Cryptorchidism is the most frequently occurring condition of disturbed sexual development in humans but as yet there is neither a satisfactory explanation nor treatment. Apart from cases of cryptorchidism associated with the androgen insensitivity syndrome, there are not usually any externally visible signs of sexual differentiation disturbance. However, there are frequent reports of 
the association between cryptorchidism and disturbed epididymidal development (Mack et al., 1961; Mininberg \& Schlossberg, 1983; Heath et al., 1984; DePalma et al., 1988; Gill et al., 1989). Failure of appropriate epididymis development could represent just one of many factors in the disturbance of testis descent (Polani, 1970). In the present work there was a highly significant correlation between suppression of epididymis development and cryptorchidism.

Flutamide-exposed males showed the unusual association of a well-developed vagina with deferent ducts opening on its top. In cases where testis descent and complete epididymis development occurred, spermatozoa together with epididymis and seminal vesicle secretions entered the 'vagina' after puberty. This condition may allow the study of spermatogenesis by taking vaginal smears. However, in many of the rats, the anatomical condition gave rise to internal genital infections, entering through the vagina, and the destruction of part or the whole of the ipsilateral epididymis and testis. This latter observation demonstrates the role played by the normal genital tract constitution in preventing ascending genital infections. In humans, genital tract malformations associated with disturbed sexual differentiation often give rise to such infections.

Prenatal exposure to flutamide affected genital development and resulted in the persistence of nipples. Despite the 'feminine' development in this respect the male-specific pattern of postnatal growth was not affected. It has been reported that sexual differentiation in relation to body growth can easily be affected by manipulation (e.g. castration or injection of steroids) after birth. The present study does not support a role for prenatal androgens in relation to body growth but, indirectly, does support a role for postnatal testicular hormones. Previous work (van der Schoot, 1980,1990 ) has provided some evidence that it is oestrogen, produced from androgen through aromatization, rather than androgens that are responsible for male-specific postnatal growth. Male internal and external genital differentiation seem separate, with respect to their 'critical period', from male body growth differentiation. This observation might have some parallel in humans affected by the androgen insensitivity syndrome (Polani, 1970; Varrela et al., 1984).

Postnatal treatment with flutamide did not further affect rats that had been exposed to the compound prenatally. Rats treated only postnatally did not show any visible sign of suppression of androgen action. While this might be unexpected in view of the strong prenatal action of flutamide, the weight of testes at autopsy provided a possible explanation. Earlier studies have shown that the exposure of male rats to flutamide leads to a rise in endogeneous production of testosterone (Södersten et al., 1975; Viguier-Martinez et al., 1983). It is possible that the feedback control of gonadotrophin secretion by testes hormones fails owing to inhibition of androgen action. Failure of feedback control, in turn, gives rise to enhanced gonadotrophin secretion and, therefore, enhanced testosterone production. The increased adult testis weight after neonatal flutamide exposure seen in the present study may indicate exposure of the developing testes to increased amounts of gonadotrophins (Ultee-van Gessel et al., 1988). Through this increased gonadotrophic stimulus in infancy, the possible defects emerging from the postnatal suppression of testosterone action could become eliminated.

Increasing abdominal pressure in newborn males exposed the everting cremaster muscle sacs. Repeating this manual procedure throughout the first 15 days of life did not facilitate testis descent in flutamide-exposed animals. This observation does not support the idea that intra-abdominal pressure plays a role in testis descent as proposed by earlier work (Frey et al., 1983).

Treatment with testosterone during neonatal life, after prenatal exposure to flutamide prior to birth, facilitated the development of cryptorchidism. This observation is difficult to reconcile with that of Hamilton (1938) who reported the induction of premature testis decent in monkeys with androgen treatment but is in agreement with a study by Baum \& Schretlen (1975) in which neonatal treatment of ferrets with testosterone resulted in cryptorchidism. Thus neonatal testosterone administration may suppress gonadotrophin secretion and, hence, the secretion of testis hormones that may play a role in testis descent. This observation further questions the therapeutic value of an androgenic hormonal approach to cryptorchidism in human infants (Hazebroek et al., 1987). 
Treatment with oestradiol during neonatal life, after prenatal exposure to flutamide, also facilitated the development of cryptorchidism. The induction of cryptorchidism in mice by pre- or postnatal treatment with oestradiol (Raynaud, 1958; Hutson et al., 1990b) has not been found in rats (Boylan, 1978; van der Schoot, unpublished). It has been reported that oestradiol-induced cryptorchidism involves the failure of the inguinal cones to develop and, therefore, of the future cremaster muscle sacs (Raynaud, 1958). In neonatally castrated rats, there was some evidence to support the inhibitory action of oestradiol on cremaster sac development (van der Schoot, 1992). The present observations with intact rats show that cremaster sacs will eventually develop even in rats treated with oestradiol in infancy after flutamide treatment before birth. However, at 80 days of age some of the cremaster sacs could not be identified. In addition, neonatal treatment with oestradiol markedly affected testis growth and permanently suppressed epididymis and deferent duct development. It remains to be determined whether the delayed growth of the cremaster sacs, the reduced testis growth and the inhibition of epididymis and deferent duct development combine to contribute to cryptorchidism. Cryptorchidism may then be judged as the final result of developmental dysfunction in the male internal genital system. It is possible that the architecture and activity of the various parts of the genital system, rather than a specific hormone, contribute to testicular descent (Heyns, 1987).

Thanks are due to I. Tabachnick (Schering Ltd, Bloomfield, New Jersey) for providing the flutamide and to P. van der Vaart and A. van Deurzen for taking care over the histological preparations.

\section{References}

Baum, M.J. \& Schretlen, P. (1975) Neuroendocrine effects of perinatal androgenization in the male ferret. Progress in Brain Research 42, 343-355.

Beasley, S.W. \& Hutson, J.M. (1988) The role of the gubernaculum in testicular descent. Journal of Urology 140, 1191-1193.

Bergh, A., Helander, H.F. \& Wahlqvist, L. (1978) Studies on factors governing testicular descent in the ratparticularly the role of gubernaculum testis. International Journal of Andrology 1, 342-356.

Boylan, E.S. (1978) Morphological and functional consequences of prenatal exposure to diethylstilbestrol in the rat. Biology of Reproduction 19, 854-863.

Brand, T., van 't Hoog, A., Slob, A.K. \& van der Schoot, P. (1989) Testicular ectopia and occurrence of epididymidal and testicular damage in rats after prenatal exposure to antiandrogens. Proceedings of the 30th Dutch Federation Meeting, Maastricht 1989, Abstract 49. Dutch Federation of Medical Biological Societies.

DePalma, L., Carter, D. \& Weiss, R.M. (1988) Epididymal and vas deferens immaturity in cryptorchidism. Journal of Urology 140, 1194-1196.

Elger, W., Neumann, F. \& von Berswordt-Wallrabe, $R$. (1971) The influence of androgen antagonists and progestogens on the sex differentiation of different mammalian species. In Hormones in Development, pp. 651-667. Ed. M. Hamburgh. Appleton-CenturyCrofts, New York.

Fentener van Vlissingen, J.M., Blankenstein, M.A., Thijssen, J.H.H., Colenbrander, B., Verbruggen, A.J.E.P. \& Wensing, C.J.G. (1988) Familial male pseudohermaphroditism and testicular descent in the Racoon dog (Nyctereutes). Anatomical Record 222, $350-356$.
Frey, H.L., Peng, S. \& Rajfer, J. (1983) Synergy of abdominal pressure and androgens in testicular descent. Biology of Reproduction 29, 1233-1239.

Gill, B., Kogan, S., Starr, S., Reda, E. \& Levitt, S. (1989) Significance of epididymal and ductal anomalies associated with testicular maldescent. Journal of Urology 142, 556-558.

Hamilton, J.B. (1938) The effect of male hormone upon the descent of the testis. Anatomical Record 70, 533-541.

Hazebroek, F.W.J., de Muinck Keizer-Schrama, S.M.P.F., van Maarschalkerweerd, M., Visser, H.K.A. \& Molenaar, J.C. (1987) Why luteinizing-hormonereleasing-hormone nasal spray will not replace orchiopexy in the treatment of boys with undescended testes. Journal of Pediatric Surgery 22, 1177-1182.

Heath, A.L., Man, D.W.K. \& Eckstein, H.B. (1984) Epididymal abnormalities associated with maldescent of the testis. Journal of Pediatric Surgery 19, 47-49.

Heyns, C.F. (1987) The gubernaculum during testicular descent in the human foetus. Journal of Anatomy 153, 93-112.

Hutson, J.M., Williams, M.P.L., S., Fallat, M. \& Attah, A. (1990a) Testicular descent: new insights into its hormonal control. Oxford Reviews in Reproductive Biology 12, 1-56.

Hutson, J.M., Watts, L.M., Montalto, J. \& Greco, S. (1990b) Both gonadotropin and testosterone fail to resolve estrogen-induced cryptorchidism in fetal mice: further evidence for nonandrogenic control of testicular descent in the fetus. Pediatric Surgery 5, $13-18$.

Jost, A., Vigier, B., Prepin, J. \& Perchellet, J. P. (1973) Studies on sex differentiation in mammals. Recent Progress in Hormone Research 29, 1-41. 
Kirk, R.E. (1968) Experimental design: procedures for the behavioral sciences. Brooks \& Cole, Belmont.

Kort, W.J., Hekking-Weijma, I. \& Vermeij, M. (1990) Artificial intra-abdominal cryptorchidism in young adult rats leads to irreversible azoospermia. European Urology 18, 302-306.

Mack, W.S., Scott, L.S., Ferguson-Smith, M.A. \& Lennox, B. (1961) Ectopic testes and true undescended testis: a histological comparison. Journal of Pathology and Bacteriology 82, 439-443.

Mininberg, D.T. \& Schlossberg, S. (1983) The role of the epididymis in testicular decent. Journal of Urology 129, 1207-1208.

Neri, R., Florance, K., Koziol, P. \& VanCleave, S. (1972) A biological profile of a nonsteroidal antiandrogen, SCH 13521 (4'-nitro-3'-trifluoromethylisobutyranilide). Endocrinology 91, 427-437.

Neumann, F., Von Berswordt-Wallrabe, R., Elger, W., Steinbeck, H., Hahn, J.D. \& Kramer, M. (1970) Aspects of androgen-dependent events as studied by anti-androgens. Recent Progress in Hormone Research 26, 337-410.

Peets, E.A., Henson, M.F. \& Neri, R. (1974) On the mechanism of the anti-androgenic action of flutamide $(\alpha-\alpha$ $\alpha$-trifluoro-2-methyl-4-nitro-m-propionotoluidide) in the rat. Endocrinology 94, 532-540.

Polani, P.E. (1970) Hormonal and clinical aspects of hermaphroditism and the testicular feminizing syndrome in man. Philosophical Transactions of the Royal Society Series B 259, 187-204.

Raynaud, A. (1958) Inhibition, sous l'effet d'une hormone oestrogène, du développement du gubernaculum du foetus mâle de Souris. Comptes Rendues des séances de l'Académie de Science 246, 176-179.

Södersten, P., Damassa, D.A., Smith, E.R. \& Davidson, J.M. (1975) Effects of a non-steroidal antiandrogen on sexual behavior and pituitary-gonadal function in the male rat. Endocrinology 97, 1468-1475.
Stanley, A.J., Gumbeck, L.G. \& Allison, J.E. (1973) Male pseudohermaphroditism in the laboratory Norway rat. Recent Progress in Hormone Research 29, 43-64.

Ultee-van Gessel, A.M., Timmerman, M.A. \& de Jong, F.H. (1988) Effects of treatment of neonatal rats with highly purified FSH alone and in combination with $\mathrm{LH}$ on testicular function and endogenous hormone levels at various ages. Journal of Endocrinology 116, 413-420.

Varrela, J., Alvesalo, L. \& Vinkka, H. (1984) Body size and shape in $46, \mathrm{XY}$ females with complete testicular feminization. Human Biology 11, 291-301.

van der Schoot, P. (1980) Effects of dihydrotestosterone and oestradiol on sexual differentiation in male rats. Journal of Endocrinology 84, 397-407.

van der Schoot, P. (1990) Sexual differentiation of body, brain and behaviour: animal studies intended to gain insight in human sexuality. In Psychoneuroendocrinology of Growth and Development, pp. 77-93. Eds A. K. Slob \& M. J. Baum. Medicom, The Netherlands.

van der Schoot, P. (1992) Androgens in relation to prenatal development and postnatal inversion of the gubernacula in rats. Journal of Reproduction and Fertility 95, 145-158.

Vigier-Martinez, M.C., Hochereau de Reviers, M.T., Barenton, B. \& Perreau, C. (1983) Effect of a non-steroidal antiandrogen, flutamide, on the hypothalamo-pituitary axis, genital tract and testis in growing male rats: endocrinological and histological data. Acta Endocrinologica 102, 299-306.

Wilkins, L. (1950) In The Diagnosis and Treatment of Endocrine Disorders in Childhood and Adolescence pp. 271-278. Thomas, Springfield.

Received 12 August 1991 